\title{
El ejercicio de la magistratura y su fiscalización administrativa y jurisdiccional en el ámbito comparado $^{1}$
}

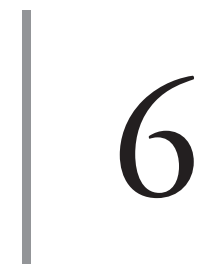

https://doi.org/10.21830/9789585284883.06

\author{
Manuel Bermúdez-Tapia ${ }^{2}$ \\ Universidad Privada San Juan Bautista \\ Carolina Pedraza Mariño ${ }^{3}$ \\ Óscar Edilson Gómez Vargas ${ }^{4}$ \\ Escuela de Aviación del Ejército
}

\section{Introducción}

En el ámbito peruano, la actividad que desarrolla el juez es una cuestión sumamente compleja, principalmente porque la posibilidad de ser foco de la crítica pública, especializada o académica es sumamente amplia.

Entre las fuentes de crítica, la más general es la emitida por el ciudadano corriente, cuyo comentario deja de lado el entendimiento del complejo

1 Este capítulo hace parte de los resultados del proyecto de investigación "Perspectivas en Derechos Humanos y Derecho Internacional Humanitario para el Ejército Nacional de Colombia" del Grupo de Investigación en Aviación Militar de la Escuela de Aviación del Ejército, registrado con el código COL0077618 y categorizado en C por Minciencias. Los puntos de vista pertenecen a los autores y no reflejan necesariamente los de las instituciones participantes.

2 Abogado (magna cum laude) de la Pontificia Universidad Católica del Perú. Magíster en Derecho y PhD en Derecho por la Pontificia Universidad Católica de Argentina. Profesor-investigador de la Universidad Privada San Juan Bautista y profesor de la Facultad de Derecho de la Universidad Nacional Mayor de San Marcos. Orcid: http://orcid.org/0000-0003-1576-9464 - Contacto: manuel. bermudez@upsjb.edu.pe

3 Capitán en el Ejército Nacional de Colombia. Especialista en Ciencias Militares para el Planeamiento, Centro de Educación Militar, Colombia. Profesional en Ciencias Militares y profesional en Administración Logística, Escuela Militar de Cadetes "General José María Córdova", Colombia. Investigadora de la Escuela de Aviación del Ejército, Grupo de investigación en Aviación Militar. Orcid: https://orcid.org/0000-0001-5055-3154 - Contacto: carolina.pedraza@buzonejercito.mil.co

4 Profesional en Ciencias Militares de la Escuela Militar de Cadetes "General José María Córdova”. Se encuentra cursando la Maestría en Gerencia de Proyectos en la Universidad Militar Nueva Granada. Es piloto de helicópteros MI-17 de la Aviación del Ejército. Actualmente se desempeña como instructor y oficial de ciencia y tecnología en la Escuela de Aviación del Ejército. Orcid: https://orcid. org/0000-0002-5371-9444 - Contacto: oscar.gomezva@buzonejercito.mil.co 
sistema jurisdiccional en cuanto a la evaluación de la normatividad aplicable al caso concreto (Sierra, 2004, p. 87). Paralelamente se registra la opinión, muchas veces subjetiva, de muchas autoridades políticas, principalmente cuando surge una situación de coyuntura. Finalmente se puede observar la crítica de los colegas, quienes usualmente asumen dos posiciones opuestas: cuestionar los fundamentos o los criterios de evaluación desarrollados en la argumentación expuesta o estar a favor de estos. Eventualmente, ambas voces se centran en lo que está siendo evaluado y no en los elementos ajenos al expediente judicial, principal elemento del que se desprende el comentario.

Así, la labor llevada a cabo por el juez es una de las más criticables en el ámbito comparativo frente a otras actividades profesionales. Dicho panorama suele ser característico de los países en los que se desarrolla el sistema jurídico romano-germánico, por cuanto existe en el subconsciente colectivo la idea de que el “juez es la boca de la ley” (Santaella López, 1995, p. 77).

En estas líneas preliminares se observa que cualquiera puede ejecutar una crítica a la labor del juez durante el desarrollo de un proceso judicial (BarreroBarrero \& Baquero-Valdés, 2020). Por otra parte, se registra que existen dos elementos en los que se focaliza la evaluación de la labor jurisdiccional del juez:

a. En primer término, está la propia "evaluación” de la producción judicial, contenida en resoluciones o sentencias. Así, existen mecanismos para "corregir" la decisión de un juez que ha quedado plasmada en una resolución de trámite o en una sentencia, como un reconocimiento a los valores constitucionales de la defensa de toda persona (Gozaíni, 2016). Dichos mecanismos están contenidos en la legislación procesal, que permite desarrollar la "doble instancia" en el ámbito jurisdiccional, la cual evita una situación de perjuicio para el justiciable que cuestiona una primera decisión sobre un tema que le genera un perjuicio.

b. Complementariamente, existen mecanismos de "fiscalización" de la labor jurisdiccional en el caso concreto de la fundamentación o desarrollo de un proceso judicial. Este mecanismo es de carácter "administrativo" y, aunque suene paradójico, es el que provoca mayores inconvenientes para la labor del juez. 
Estos mecanismos son especialmente de control y verificación de la función judicial, frente a las expectativas que tiene el Poder Judicial, el Consejo Nacional de la Magistratura (reemplazado a partir del año 2020 por la Junta Nacional de Justicia) y la propia comunidad. Por lo tanto, de por medio está no solo el "derecho" del justiciable, sino también la propia "función jurisdiccional" en evaluación, por cuanto una deficiente labor en dicho ámbito podría provocar una crisis social e inclusive el propio decaimiento del Estado de derecho. Dada su elevada importancia, en principio por su origen constitucional detallado en el artículo 138 de la Constitución, esta función de fiscalización se desarrolla en tres niveles:

i. La que ejecuta el propio Poder Judicial, con medios administrativos de evaluación de la labor jurisdiccional, a cargo del Órgano de Control de la Magistratura (OCMA) y sus dependencias en cada Distrito Judicial.

En este ámbito se evalúa la labor jurisdiccional si esta ha cumplido con las siguientes características:

(i) Se han llevado a cabo las disposiciones normativas aplicables al proceso.

(ii) El proceso se ha desarrollado correctamente.

(iii) El juez de la fundamentación de una resolución o sentencia ha seguido los precedentes aplicables al caso expuesto en el expediente.

Estos elementos están principalmente vinculados a un ámbito de evaluación administrativo, antes que a la propia acción de la labor jurisdiccional (Alarcón Sotomayor, 2010, p. 504).

ii. La que ejecuta un órgano de carácter administrativo al propio Poder Judicial (Vidal et al., 2005, p. 330). En el caso peruano esta fiscalización se focaliza en la labor que ejecuta el Consejo Nacional de la Magistratura sobre el "trabajo" del juez no solo durante siete años — conforme al periodo de vigencia de un nombramiento-, sino respecto de casos de evidente negligencia o niveles de corrupción (Plaza, 2001, p. 286). 
iii. La que se ejecuta en el ámbito penal, cuando existe una denuncia por prevaricato y un fiscal del Ministerio Público desarrolla la evaluación de la aplicación de una norma en el caso concreto de un expediente en estudio en el despacho del juez (Espinoza Goyena, 2004, p. 462).

Se observa que existe en este ámbito un contexto sumamente complejo que nos permite presentar el siguiente esquema de trabajo.

\section{El control jurisdiccional: la doble instancia}

La práctica legal en el país tiene un patrón característico: un elevado contenido subjetivo en el ámbito de la defensa de derechos, intereses y posiciones, condiciones que se determinan en el ámbito jurisdiccional, sin un criterio determinado de predictibilidad (De Belaúnde, 2006, p. 15). Esto quiere decir que dada la elevada litigiosidad de la práctica legal en el país, los resultados de un proceso judicial son también complicados de predecir, principalmente porque existen tantos criterios de interpretación de normas a casos particulares como magistrados hay. Factor que lamentablemente eleva el contexto negativo en la labor jurisdiccional y genera situaciones en las que se evidencia temeridad y malicia procesal (Picó, 2013). Estas últimas en el Perú no suelen ser sancionadas, con lo cual los propios jueces ejecutan acciones vinculadas a un contexto de corrupción por inacción (Ugarteche, 2005, p. 58).

Inclusive en el propio ámbito funcional de un magistrado, este puede "resolver" de dos maneras totalmente contradictorias, cuando la materia resulta a primera vista una cuestión de procedimiento. Estas circunstancias se presentan, por ejemplo, en el ámbito jurisdiccional de familia, en el que, sobre un mismo menor, un juez puede resolver casos de alimentos y otro juez, de otra instancia o ciudad de competencia, puede resolver un caso de tenencia (Solórzano, 2017, p. 80).

Como segundo ejemplo se puede citar la evaluación casos societarios en el ámbito judicial, en los que es posible visualizar el seguimiento de procesos paralelos con el mismo fin: un "proceso de ejecución" y un "proceso de conocimiento", que suelen provocar resoluciones contradictorias entre ambos (Carrillo Lozada \& Gianotti Paredes, 2013, p. 374). 
Así, se evidencia una contradicción de posiciones en el ámbito jurisdiccional, porque la ley (Código Procesal Civil y Leyes Especiales) permite que las partes puedan atomizar sus pretensiones y, con ello, se provoca el error en la práctica judicial. Este factor nos permite plantear un ejemplo de cómo "una sola cuestión" puede generar una multiplicidad de posiciones en el magistrado al momento de fundamentar una decisión.

Cierto es, también, que cuando el juez evalúa las posiciones de los justiciables está condicionado a la arbitrariedad de planteamientos que los abogados suelen exponer en sus escritos, por lo cual se considera que, adicional a la tutela de "derechos" y de "intereses", existe la práctica de "defensa de posiciones" (Salas Villalobos, 2012, p. 294).

Así, podemos determinar conceptualmente lo siguiente:

a. La tutela de derechos se fundamenta en la interpretación literal de la norma, que permite la ejecución de una acción de naturaleza jurisdiccional a favor del justiciable. Salvo condiciones y situaciones en las cuales la misma ley impone un criterio de limitación de derechos. Por ejemplo, en caso de necesidad pública, la tutela de derechos deviene de lo dispuesto expresamente por dicha norma. Este tipo de situación es la que, en términos estadísticos, presenta menos contradicciones en el ámbito jurisdiccional.

b. La tutela de intereses, si bien es un elemento muy cotidiano en el ámbito jurisdiccional nacional, presenta una cuestión vinculada a la aplicación favorable de la norma en cuanto a su extensión. En este sentido, la ley no indica en forma expresa una condición o situación favorable al justiciable, pero permite el desarrollo de un argumento que "desarrolla" el fundamento de la tutela planteada por el justiciable (Guerra Cerrón, 2011, p. 145). Así, la aplicabilidad de principios de orden constitucional resulta fundamental para el desarrollo de la tutela de intereses.

De este modo, el principio pro homine, el de progresividad y el de complementación de normas le permiten a un justiciable presentar un argumento sólido que influye en la decisión del juez para la materialización de una expectativa en la tutela de una pretensión caracterizada por su objetividad. 
Este factor es el que eventualmente ha permitido elevar el número de peticiones de intervención en el ámbito constitucional por parte del Tribunal Constitucional en el Perú, porque la evaluación de situaciones constitucionales en el ámbito jurisdiccional ha generado la contradicción entre el Tribunal Constitucional y el Poder Judicial; y este último ha tenido que sujetarse a las disposiciones jurisdiccios nales del primero (Figueroa Gutarra, 2012).

c. Sin embargo, en un tercer ámbito tenemos la defensa de "posiciones” (Bermúdez-Tapia, 2012), que la propia doctrina nacional no suele desarrollar, principalmente, porque existe un elemento subjetivo demasiado elevado respecto de las acciones de los justiciables. Dicho comportamiento se registra con un elevado nivel de incidencia en el ámbito jurisdiccional.

De este modo, el justiciable plantea un argumento subjetivo que carece de elementos lógicos o referenciales en el ámbito de una complementación probable (la interpretación de la ley o la aplicación de algún principio de orden constitucional o procesal). En algunas situaciones se "suele" contar con la venia del juez, de forma que se genera una resolución o una sentencia que provoca una impugnación inmediata. Podemos citar, por ejemplo, los casos siguientes:

i. No se presentan elementos probatorios para justificar una acción de defensa de algún derecho o de un interés. En el Perú, debido al incremento de los casos de violencia contra la mujer, es viable denunciar a una persona sin un medio probatorio y automáticamente generar una situación de detención contra el "acusado", sin que se registre un "debido proceso" a raíz de dicha acusación. Esta situación, que atenta contra el debido proceso y la presunción de inocencia, está regulada en la Ley N.o 30364 (Mujica, 2012, p. 169).

ii. La fundamentación del argumento expuesto está vinculada a una cuestión sumamente referencial en lo personal, sin aludir a un elemento que lo sostenga en lo teórico o en lo procedimental en el desarrollo del proceso (Lebón \& Maier, 2006, p. 413). 
En este sentido, la ley peruana permite el desarrollo de planteamientos ambiguos, abiertos y oscuros en la formulación de los petitorios en los procesos judiciales, principalmente porque ha procurado "flexibilizar" algunos procesos para así optimizar la "tutela de derechos" de las partes demandantes. Esto se evidencia en los procesos de alimentos y de ejecución de desalojo, que por ser procesos flexibles no requieren una mayor acreditación de los elementos de hecho expuestos en la demanda (Avendaño Valdez, 2013, p. 352).

iii. La extrapolación de fundamentos frente al argumento de la contraparte. Esto es, la negación o exclusión de derechos a la parte contraria, por el solo hecho de que una parte no está en condiciones de aceptar o los derechos o las pretensiones que se han expuesto en contra suya. Situación que explica el elevado contexto de las reconvenciones procesales, que son la "respuesta" del demandado a la acción del demandante y que eventualmente implica una denuncia administrativa al juez por haber admitido la primera demanda (Figueroa Ortiz, 2009).

De este modo, como representación de estas situaciones, podemos aludir a algunos casos que son usuales en el ámbito nacional.

i. En el ámbito jurisdiccional de familia, la negación de pedidos de un régimen de visitas o de reformulación de un pedido de alimentos usualmente está condicionada a "posiciones" de las partes y no a elementos objetivos que se pudieran observar en el desarrollo del proceso (Ponce Alburquerque, 2017).

ii. En el ámbito jurisdiccional penal, la solicitud de "detención preliminar" usualmente está vinculada a un "peligro procesal", pero más allá de esta afirmación no se suele observar una mayor contundencia en la necesidad de limitar o condicionar un derecho fundamental tan importante para la persona: su propia libertad (Rey, 2012, p. 355).

iii. En el ámbito jurisdiccional civil, en casos de ejecución de medidas cautelares, la fundamentación de la aprobación de la contracautela en la evaluación de derechos de orden patrimonial suele ser ajena a la realidad económica en la que desa- 
rrolla el proceso (Instituto de Investigaciones de la Escuela Profesional de Turismo y Hostelería de la Universidad de San Martín de Porres, 2005, p. 113).

Así, en sencillos ejemplos, es posible señalar que la práctica jurisdiccional nacional suele registrar casos en los cuales las partes procesales no debaten un derecho o casos en los que la interpretación de una norma para la materialización de un derecho en mérito a un planteamiento de una pretensión (interés) eventualmente podría ser determinada como improcedente en la primera evaluación de la demanda.

Sin embargo, por el solo cumplimiento de las formalidades del Código Procesal Civil — si nos limitamos a este ámbito jurisdiccional—, las demandas suelen ser "admitidas" a trámite sin evaluarse en forma objetiva las pretensiones formuladas, que en algunos casos bien pudieran ser defenestradas inmediatamente.

Sin embargo, el comportamiento de las partes procesales genera un desarrollo y, con ello, su evaluación tanto en forma parcial en la emisión de resoluciones (i) como en forma conclusiva cuando se emiten sentencias (ii). Con base en esto, se invoca la intervención del Estado en la atención de conflictos de intereses, sin importar muchas veces su alcance, tanto en lo patrimonial como en lo temporal, porque los plazos y condiciones son un factor que incide negativamente en los justiciables, con lo cual se suelen generar casos de abandono procesal.

Sea cual fuere la situación, las partes procesales son muy críticas con respecto a la labor del juez y para ello emplean varios instrumentos, que son válidos y legítimos para cuestionar una decisión, pero que eventualmente se transforman en el desarrollo del conflicto en el ámbito judicial en situaciones maliciosas y temerarias. Así, podemos mencionar las más usuales:

\section{a. La reconvención}

Un ejemplo aplicable a la fundamentación de nuestra posición podría ser la evaluación del III Pleno Casatorio Civil, desarrollado por la evaluación de la Casación N.o -2010-4664Puno, divorcio por separación de hecho (Poder Judicial, 2010). 
Téngase en cuenta que el desarrollo del conflicto material entre las partes fue "promovida" en lo jurisdiccional por el demandante que hizo el abandono de hogar (y abandono material de su familia) ante el Poder Judicial. La parte demandada, luego de un periodo de procrastinación, justificó su defensa y expuso el verdadero contexto del conflicto familiar.

En este ámbito, la primera decisión el juez de admitir a trámite el proceso finalmente devino a favor de la parte "más débil" del conflicto entre las partes procesales, provocando en forma implícita el reconocimiento de algunas condiciones que se suelen generar y presentar en el desarrollo de conflictos familiares, como la presentación de partes "fuertes o débiles" y en mérito a ello atender el "caso en función al contexto".

b. Las excepciones y defensas previas

Estos recursos, de acuerdo con Bullard (1993, p. 155), son los siguientes:

i. Excepción de incompetencia, por razón de territorio, materia, grado o por cuantía.

ii. Excepción de incapacidad del demandante o de su representante.

iii. Excepción de representación defectuosa o insuficiente del demandante o del demandado.

iv. Excepción de oscuridad o ambigüedad en el modo de proponer la demanda, lo cual está vinculado esencialmente a una práctica temeraria o maliciosa de parte de quien accede a la tutela jurisdiccional efectiva con la interposición de una demanda por uso de su derecho a accionar.

v. Excepción de falta de agotamiento de la vía administrativa.

vi. Excepción de falta de legitimidad para obrar del demandante o demandado.

vii. Excepción de litispendencia.

viii. Excepción de cosa juzgada.

ix. Excepción de desistimiento de la pretensión.

x. Excepción de conclusión del proceso por conciliación o transacción. 
xi. Excepción de caducidad.

xii. Excepción de prescripción extintiva.

xiii. Excepción de convenio arbitral.

Como se observa, las partes procesales pueden ejecutar una acción en forma inmediata para la defensa de sus derechos en mérito no al fundamento de sus argumentos, sino a elementos materiales que determinan la viabilidad del mismo proceso judicial en forma primigenia.

Punto particular en este contexto, es que las "excepciones procesales" solo son evaluadas en la sentencia, esto es, al final del proceso y no en su etapa preliminar. Ello genera el seguimiento de un proceso muchas veces innecesario, al registrarse el inconveniente procesal en su etapa inicial. Tal es la condición por la cual las denuncias por infracción al deber de dirigir el proceso son constantes en el ámbito jurisdiccional nacional y limitan la carrera del juez, porque el Consejo Nacional de la Magistratura suele tomar conocimiento de esa negligencia y la califica en forma negativa al momento de la "ratificación" del magistrado cada siete años (Rioja Bermúdez, 2011, p. 326).

c. La reposición

Este recurso procede contra los decretos emitidos por el juez con el fin de que este los revoque.

En el mismo proceso y ante el mismo juez, las partes procesales plantean la "reposición" de una resolución judicial de mero trámite, a razón de lo cual el recurso suele ser admitido en el trámite del proceso, porque generalmente está vinculado a los procedimientos administrativos en el desarrollo del expediente judicial.

\section{d. La apelación}

A efectos de provocar la intervención de un órgano jurisdiccional superior para la evaluación de una decisión primigenia, se acude a la apelación, con lo que en esencia se desarrolla el principio constitucional de la doble instancia.

En este punto, surgen dos contextos muy diferentes: es posible "apelar" una decisión de un juez de primera instancia y también es viable "apelar" la decisión de una Sala Superior (órgano jurisdic- 
cional de segunda instancia), pero en este caso varía su denominación y se llama "recurso de casación".

Sin embargo, en ambos casos la ley procesal peruana no es muy estricta en la identificación del "error judicial" y por ello la "instancia de apelación" y la propia Corte Suprema, cuando ejecuta una función casatoria, finalmente "resuelve como si fuera un órgano de instancia” (Gaceta Civil y Procesal Civil, 2014, p. 13).

e. La queja

Conforme al artículo 401 del Código Procesal Civil, la queja tiene por objeto el reexamen de la resolución que declara inadmisible o improcedente un recurso de apelación.

f. La aclaración y corrección de resoluciones

Usualmente presente cuando en la parte resolutiva de una decisión judicial (resolución o sentencia) las partes observan un elemento que resulta ambiguo en cuanto a su definición o determinación (Monroy Gálvez, 2010).

Finalmente, todos estos elementos e instituciones procesales permiten la viabilidad de una práctica jurisdiccional que puede mejorar su propia decisión o plantear el reexamen de una decisión por intervención de un órgano jurisdiccional diferente y superior. El principio de la doble instancia es, pues, el mejor elemento para poder "juzgar” la labor jurisdiccional de forma objetiva.

Una decisión equivocada o sin fundamento (tanto parcial como completa) podrá ser cuestionada en una instancia superior, que corregirá dicha situación a favor del justiciable y provocará, en esencia, que el "derecho" — tanto en el ámbito subjetivo para el justiciable como para la comunidad — se encuentre a buen recaudo, con lo cual se desarrolla la mejor fiscalización para la labor jurisdiccional. Un método diferente a estos mecanismos prácticamente constituiría una limitación a la autonomía jurisdiccional del juez.

\section{La fiscalización administrativa de la labor del juez}

En este ámbito intervienen dos instancias, representadas por dos órganos de carácter autónomo a nivel constitucional: 
a. El propio Poder Judicial, con sus instancias de fiscalización de la labor jurisdiccional a cargo del Órgano de Control de la Magistratura (OCMA) (Rubio Correa, 2006, p. 292).

b. El Consejo Nacional de la Magistratura, que puede ejecutar:

i. Un proceso de destitución, por falta calificada como grave, en el ejercicio jurisdiccional (Organisation for Economic Co-operation and Development , 2017, p. 228).

ii. Un proceso de ratificación del juez, que por determinación de la Constitución se desarrolla cada siete años.

Sin embargo, en este punto, lo que se "cuestiona" no es en esencia el "contenido mismo de la resolución o sentencia" emitida por el juez, sino un comportamiento procesal o jurisdiccional respecto del desarrollo del proceso $y$, con ello, la diferencia en cuanto a la determinación de la "naturaleza" del procedimiento a ser ejecutado (Bermúdez-Tapia \& Sierra-Zamora, 2019).

En este ámbito, las decisiones de la OCMA o de sus órganos inferiores suelen ser sumamente referenciales para la evaluación del juez en los procesos de ratificación ante el Consejo Nacional de la Magistratura. En este ámbito se puede observar una diversidad de casos:

a. Procedimientos de investigación que han concluido en el archivamiento de un caso.

Cuando así sucede, el registro estadístico opera a favor del juez en un proceso de ratificación en el cargo, por cuanto las denuncias administrativas no han conllevado el registro de alguna falta administrativa.

b. Procedimientos de investigación de un caso que han provocado una sanción administrativa.

El contexto de la "falta" es referencial en la evaluación que ejecutará el Consejo Nacional de la Magistratura. Por ello se dividen las sanciones, que pueden ser por negligencia en el seguimiento del proceso (lentitud procesal) o por actuación deficiente en el proceso, que se acredita con el registro de algún procedimiento contrario a la ley.

c. Procedimientos de investigación que han provocado la recomendación del Poder Judicial para que el Consejo Nacional de Magistratura 
proceda a destituir a un magistrado. Generalmente hay vinculación con casos de corrupción manifiestos.

Como todo procedimiento administrativo, está sujeto a una evaluación tanto administrativa como jurisdiccional, pero en este punto surge un factor usualmente "observado" pero pocas veces "cuestionado": la elevada discrecionalidad de los órganos de fiscalización en cuanto a la decisión que imponen, que suele ser excesiva.

Como toda organización jerárquica y con tendencia a la verticalidad en cuanto a la funcionalidad, según el cargo que se desempeñe, el Poder Judicial suele generar una categorización funcional en sus propios trabajadores. Así, los magistrados son un universo totalmente distinto al de los asistentes o auxiliares jurisdiccionales. Entre los primeros, el nivel y la titularidad en el cargo generan también una cuestión subjetiva que se traduce en las acciones de fiscalización sobre el evaluado que tiene menor nivel en el cargo.

De este modo, los Jueces Especializados suelen ser muy reservados respecto de las decisiones que le son impuestas por las Salas Superiores en un proceso en apelación. Obsérvese, por ejemplo, cómo los jueces superiores redactan la "remisión" o los fundamentos cuando se revoca una decisión.

Situación similar se presenta cuando los jueces superiores son evaluados por la Corte Suprema, todo lo cual se amplía en forma negativa cuando se ejecuta una labor de fiscalización administrativa en la OCMA y sus órganos dependientes.

En el ámbito de las competencias del Consejo Nacional de la Magistratura se da la misma situación. Los Consejeros suelen ser sumamente severos en los procesos de fiscalización y, en la actualidad, bien se podría cuestionar a un abogado que se postula al cargo de juez, en cuanto a su valor moral, si un Consejero le impugna una filiación o no paga alimentos a favor de su hijo en su proceso de nombramiento para un cargo de alta representatividad social.

\section{La fiscalización en el ámbito penal de la labor judicial}

En este ámbito, la cuestión en evaluación es la "acción” final de no hacer lo dispuesto en la norma por parte del juez. Esto hace que su labor resulte cues- 
tionable desde el punto de vista de la interpretación literal de la norma, pero eventualmente permite la defensa del juez en dos niveles:

a. Cuando fundamenta la inaplicación de la norma al caso concreto, en mérito a fundamentos de orden constitucional principalmente.

b. Cuando el juez aplica un criterio de "equidad" en la decisión abordada, principalmente, si los "fundamentos legales" quedan fuera de un contexto en el cual las partes procesales han desarrollado situaciones muy especiales, que exigen que el juez prácticamente desarrolle derecho, porque de lo contrario no ejecutaría su labor para la solución de un conflicto material.

\section{Conclusiones}

Tras la evaluación preliminar de algunos mecanismos de control sobre la labor del juez, debemos señalar que este es un profesional y una persona que, si bien puede equivocarse, el propio derecho permite que la ley encuentre un mecanismo de solución a favor del justiciable que resultase afectado por una mala acción.

Sin embargo, la ley queda obsoleta cuando la labor del juez se desarrolla en mérito de una negligencia maliciosa o de una condición vinculada a actos de corrupción. Esto nos permite señalar que tales casos, si bien son pocos, resultan muy representativos en la actualidad, puesto que las malas decisiones de algunos jueces provocan la crítica a todo el Sistema de Impartición Jurisdiccional, lo que restringe la legitimidad del Poder Judicial ante la misma comunidad.

\section{Referencias}

Alarcón Sotomayor, L. (2010). Derecho administrativo sancionador. Editorial Lex Nova.

Avendańo Valdez, J. (2013). 35Discusión en torno al Cuarto Pleno Casatorio Civil sobre el concepto de posesión precaria. Ius et Veritas, 23(47), 352-359.

Barrero-Barrero, D., \& Baquero-Valdés, F. (2020). Objetivos de Desarrollo Sostenible: un contrato social posmoderno para la justicia, el desarrollo y la seguridad. Revista Cientifica General José Maria Córdova, 18(29), 113-137. https://doi.org/10.21830/19006586.562 
Bermúdez-Tapia, M. (2012). Derecho procesal de familia. Editorial San Marcos.

Bermúdez-Tapia, M., \& Sierra-Zamora, P. A. (2019). La violación a los derechos humanos de las familias afectadas en conflictos armados internos en Colombia y Perú en la Corte Interamericana de Derechos Humanos. Direitos Sociais e Politicas Públicas (Unifafibe), 7(3), 547-569. https://doi.org/10.25245/rdspp.v7i3.673

Bullard, A. (1993). El derecho civil peruano: perspectivas y problemas actuales. PUCP.

Carrillo Lozada, A., \& Gianotti Paredes, S. (2013). Cosa juzgada vs. ¿cosa juzgada?: sobre la inmutabilidad de las resoluciones judiciales provenientes del proceso de ejecución. Ius et Veritas, 23(47), 374-385.

De Belaúnde, J. (2006). La reforma del sistema de justicia: ¿En el camino correcto? Breve balance de su situación actual y de los retos pendientes. Instituto Peruano de Economía.

Espinoza Goyena, J. (2004). A propósito de la Ley de celeridad y eficacia procesal. Ley No 28117 del 9 de diciembre 2003. En J. Hurtado Pozo,. La reforma del proceso penal peruano: anuario de derecho penal 2004. PUCP-Universidad de Friburgo.

Figueroa Gutarra, E. (2012). La exigencia constitucional del deber de motivar. ADRUS.

Figueroa Ortiz, E. (2009). La compensación y la reconvención en el proceso laboral. Revista de la Maestría en Derecho Procesal, 3(1), 1-11.

Gaceta Civil y Procesal Civil. (2014). La valoración de pruebas en sede casatoria. Gaceta Civil y Procesal Civil, 8.

Gozaíni, O. (2016). Garantías, principios y reglas del proceso civil. Universidad de Buenos Aires.

Guerra Cerrón, M. (2011). Manual del Código Procesal Civil. Gaceta Jurídica.

Instituto de Investigaciones de la Escuela Profesional de Turismo y Hostelería de la Universidad de San Martín de Porres. (2005). El impacto económico de la cultura en Perú. Universidad de San Martín de Porres.

Lebón, N., \& Maier, E. (2006). De lo privado a lo público: 30 años de lucha ciudadana de las mujeres en América Latina. Siglo XXI.

Monroy Gálvez, J. (2010). La formación del proceso civil peruano: escritos reunidos. Communitas.

Mujica, J. (2012). Construction problems of criminological indicators and comparative situation of femicide in Peru. Anthropologica, 30(30), 169-194.

Organisation for Economic Co-operation and Development. (2017). Estudio de la OCDE sobre integridad en el Perú: Reforzar la integridad del sector público para un crecimiento incluyente. OECD Publishing.

Picó, J. (2013). El principio de la buena fe procesal. Bosch Editor.

Plaza, O. (2001). Perú: actores y escenarios al inicio del nuevo milenio. PUCP.

Poder Judicial. (2010). Tercer Pleno Casatorio Civil. Poder Judicial.

Ponce Alburquerque, J. (2017). Familia, conflictos familiares y mediación. Ubijus.

Rey, F. (2012). Los derechos en Latinoamérica: tendencias judiciales recientes. Editorial Complutense.

Rioja Bermúdez, A. (2011). El nuevo proceso civil peruano. Adrus.

Rubio Correa, M. (2006). El Estado peruano según la jurisprudencia del Tribunal Constitucional. PUCP. 
Salas Villalobos, S. (2012). Efectos de la aplicación de la adecuación en los petitorios y providencias cautelares. Ius et Veritas, 22(44), 294-308.

Santaella López, M. (1995). Montesquieu: el legislador y el arte de legislar. UPCO.

Sierra Cristóbal, R. (2004). La libertad ideológica del juez. Tirant lo Blanch.

Solórzano Flores, A. (2017) La asignación anticipada en los procesos de alimentos: impacto de la Ley 29803. Fondo Editorial del Congreso del Perú.

Ugarteche, O. (2005). Vicios públicos: poder y corrupción. Sur.

Vidal, J., Díaz, V., \& Rodríguez, G. (2005) Temas de derecho administrativo contemporáneo. Universidad del Rosario. 